\title{
Adoption of E-Health Records Management Model in Health Sector of Iraq
}

\author{
Ali Fahem Neamah' and Mohd Khanapi Abd Ghani ${ }^{2}$ \\ 'University of Wasit, Collage of Computer and Information Technology, Iraq \\ ali_alyasree@yahoo.com \\ UTeM, FTMK, Melaka, Malaysia \\ khanapi@utem.edu.my
}

\begin{abstract}
Objective: To develop a model for Iraqi Electronic health record adoption by investigating the effects of the proposed exogenous variables. Methods: "This study is a quantitative approach to collect data from a selected sample of the healthcare providers population in Iraq. The sampling frame for this study consisted of four hospitals in Iraq. Diffusion of innovation theory and social exchange theory, the research model was basically developed based on Technology-Organization-Environment framework by extending the individual context. The target population was the healthcare worker in the selected hospitals. Findings: The result shows, out of 13 factors studied there were 12 supported factors while there was 1 factor which is not supported. Application: The present work is focused on the application area of healthcare and medical records with specific target of Iraq. The results can be further generalized and evaluated from other locations so that the overall predictions can be done for knowledge discovery.
\end{abstract}

Keywords: Developing Countries, EHR, E-health, Factors, Model, Iraq

\section{Introduction}

Information and Communications Technologies (ICTs) include a group of powerful tools to process, store, collect, and exchange healthcare related information $\stackrel{1}{-}$. Due to that, ICT can improve quality, safety, and cost effectiveness of health-related services. Among the programs of ICT in health-related sector, the E-Health Records (EHRs) is considered as the backbone promoting the integration of several tools (for example. test ordering, emergency information, electronic prescription, digital imagery, decision-support system, and telemedicine) which may increase the customer base of evidence directly into medical decisions. By employing such evidence within daily clinical procedures can enable a safer together with more efficient healthcare systems.

Professionals, patients, and institutions are therefore expected to benefit through EHRs adoption. International literature facilitates various benefits of EHR intended for patients. One of the most important benefits revealed is the improved quality of proper care caused from patients obtaining their crucial health data attainable to their various healthcare providers. Based on related disease management applications $s^{3}$, EHR can support motivated citizens to be able to actively take part regarding decisions about their health. E-Medical Records (EMRs) and Electronic Health Records (EHRs) are regarded as synonyms within healthcare industry ${ }^{4}$. The EHR system is

${ }^{*}$ Author for correspondence 
also a new tool that gives decision making and knowledge exchange among healthcare specialists by offering them with relevant, well-timed, as well as up-to-date of information ${ }^{5}$.

An EHR system is a software that enables medical facilities to create, organize, edit, store, and retrieve patient record on a computer. Also, about 30 years ago, the first electronic health records were introduced as a computer-based health record system with limited accessibility to medical care providers by using that single computer ${ }^{6}$. However, within the last three decades, EHRs have developed over time to include very innovative digitalized formats for medical practitioners to record and check health data as well as, in some cases, the accessibility of health information which is stored online. A number of healthcare providers have been prepared to develop and employ their own proprietary EHR systems and are, therefore, ahead of the rest of the healthcare industry; some of these healthcare providers are the Veterans Administration, which has implemented its own system called My Health e Vet, and Kaiser Permanente with their own EHR system called My Health Manager ${ }^{16}$.

The Electronic Health Records (EHRs) is an essential application of ICTs to the health-related sector. EHRs implementation is anticipated to provide benefits pertaining to professionals, organizations, patients, and the population in general. These benefits are not able to achieve without the EHR adoption by medical professionals. However, the impact of organizational and individual factors in deciding on the adoption of EHRs is still unclear.

Earlier researchers have recognized the advantages of HER ${ }^{7}$. Benefits included enhanced clinical practice strategies, reduced medication errors (giving the wrong drugs, unfavorable drugs interactions, or even hand writing error), and increased distribution of preventive health services.

Quite a few developing countries face difficulties locating resources, tracking chronic diseases, along with decreasing medical errors because of the lack of technologies ${ }^{8}$. Additionally, patient deployment computerized systems are dependent on organizational or local needs?. This scenario contains true in develop- ing countries such as Iraq. The manager of medical records office provided the researcher a journey in Port of General Hospital in Spain to realize the current workflow regarding health record system. This visit exposed that the big hospitals inside Port of Spain, as an example Port of General Hospital in Spain do not own an e-Health Records system. Nevertheless, some public and private hospitals, like James Medical Complex and Clair Medical Center are implementing patient information systems with regard to administrative functions for example appointments and billing ${ }^{10}$. Indeed, in Iraq, the adoption and diffusion rate of information systems in the healthrelated sector is quite poor when compared with other sectors like finance, manufacturing, transportation, and retail industries ${ }^{\underline{11}}$.

\section{Background}

The adoption of EHRs has been in place for over 30 years and has been supported by many national leaders, medical organizations, privacy advocates, and legislation. The prior studies presented an historical timeline of the challenges posed with the adoption of e-heath records and the consumer-health care provider communication dynamic. Historical data is beneficial in understanding how the adoption process has evolved and how the many challenges in adoption of these systems have been addressed.

The benefit of this study is that recording the consumer information for easy access could provide information for healthcare leaders to develop communication plans, community services, or consumer training to ensure consumer awareness of the implications in using EHRs. Improvement in recording the data would be beneficial in the adoption of EHR systems and promote change in how to record information of the patients. Other benefits include understanding the consumer perspective on communication through the measurement of satisfaction with health care or information provided.

This background of studies provided empirical evidence from studies conducted in EHR adoption and communication. The studies previously conducted will provide information on current trends in communication and systems implementation on a national and global 
level. The literature review section will be presented an historical perspective of the evolution of technology and health records, consumer satisfaction, and the effects on communication between the healthcare provider and the consumer.

\section{Research Model and Hypothesis}

The current study comes within the broad theoretical field of technology adoption. The research model proposes the adoption of EHR as a dependent variable. This canbe captured the level of intention that healthcare institutions have to adopt EHR. The intent is to adopt is utilized commonly as a dependent variable in the literature organizational IT based adoption» ${ }^{12}$. Independent variables will be categorized in four contexts 1) Individual 2) Organizational;2) Technological, and 3) Environment. As mentioned earlier, variables affiliated with these four contexts are identified based on the current review of TOE framework, DOI theory, and Institutional Theory, Theory of Reason Action (TRA), TAM, and Social

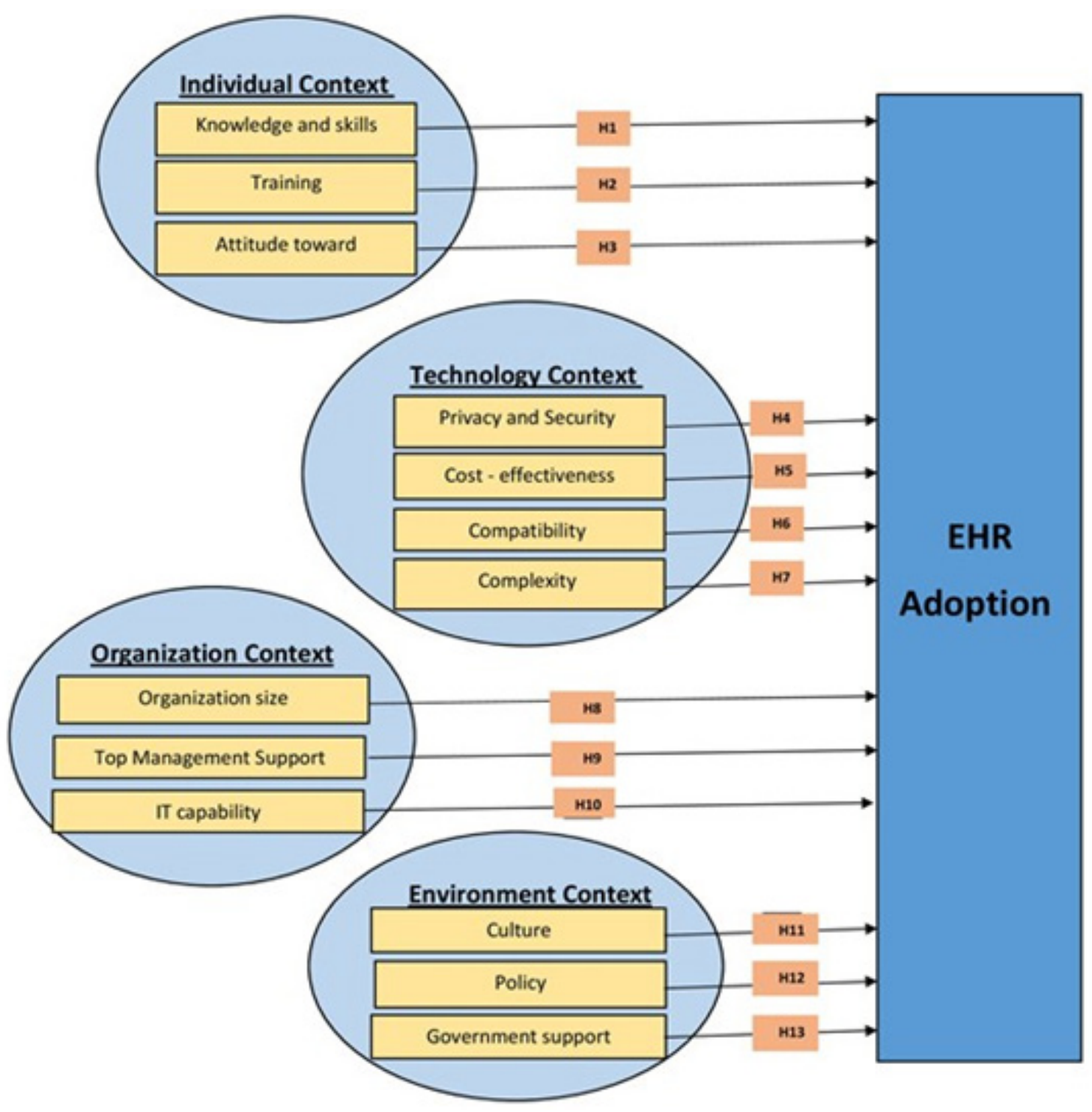

Figure 1. Hypothesis Model. 
Exchange. After that, these contexts and variables have conceptualized to be studied in this research. Figure 1 shows that the main conceptual model of this study.

\subsection{Individual Context}

Within the Individual context, there are three factors that affect the adoption of EHR systems. These factors are: Knowledge and skills, Training, and Attitude toward .

\subsubsection{Knowledge and Skills}

The lack of computer proficiency among physicians, and healthcare staff, aging hardware in addition to the lack of software usability and knowledge in EHRs software systems have contributed to the delay in the adoption of effective EHRs systems. There have been many studies documenting the causes behind the delay in the successful implementation of EHRs systems that have identified various reasons for the delay ${ }^{13}$. Physicians and medical staff in Iraq don't all possess the computer skills necessary to operate EHRs systems. Furthermore, the training needed to provide the computer skills that are needed to operate the software is quite time consuming due to the initial level of those who are to receive training. Also, complete implementation of these systems is time consuming even for hospitals that have staff with adequate computer skills. The researcher considered formulating the following hypothesis:

H1: Knowledge and skills will have a positive effect on the adoption of EHR systems in Iraqi healthcare institutions.

\subsubsection{Training}

The training is no less important than the funding or infrastructure particularly to understand the essentials of EHRs equipment and its management ${ }^{14}$. Trained nurses and physicians who are cognizant of the functions and processes of EHRs applications are necessary for conducting such training sessions. Furthermore, providing training and seminars for doctors and decision makers is highly important, because if they value the benefits of technology in the medical field, they will reap the benefits of the adoption of EHRs and facilitate its application ${ }^{15}$. In order to provide scenario-based training effectively, it is important to conduct research in the areas of training and implementation methods along with system design as they pertain to user adoption rates. There is no denying that wide system adoption and successful systems primarily require good designs complying with well-established usability and user satisfaction rules. The researcher considered formulating the following hypothesis:

H2: Training will have a positive effect on the adoption of EHR systems in Iraqi healthcare institutions .

\subsubsection{Attitudes Towards}

Understanding how Physicians attitudes towards the adoption of EHR systems are essential to overcoming these barriers and gaining wider acceptance to technology in the healthcare industry. The rating assigned by physicians on the beliefs and attitudes toward the barriers determined the typology of physician profiles. The patterns of similarities and dissimilarities in perspectives culminated into factors of adoption, which in turn guided the roadmap for implementation of interventions for minimization of risks. The ultimate objective was to increase diffusion of the EHR systems in the health industry. The researcher considered formulating the following hypothesis:

H3: Attitude toward will have a positive effect on the adoption of EHR systems in Iraqi healthcare institutions.

\subsection{Technology Context}

Within the Technology Context, there are four factors that affect the adoption of EHR systems. These factors are: Privacy and Security, Cost, Compatibility, and Complexity.

\subsubsection{Privacy and Security}

The first factors that are considered barriers to nationwide adoption of the EHRs systems in Iraq would be the concept of patient privacy. Privacy concerns remain high in a technology that by design is easily accessible. 
Brandeis and Warren define privacy as the right "to be let alone" (2014). The other definition given by Richard Rognehaugh is as the right of an individual to keep information about themselves from being disclosed to others the claim of individuals to be let alone, from surveillance or interference from other individuals, organizations or the government $\frac{16}{6}$. The important point which needs to be stressed is the increase and growth of understanding and awareness of personal privacy of patients $s^{17}$. The researcher considered formulating the following hypothesis:

H4: Privacy and Security will have a positive effect on the adoption of EHR systems in Iraqi healthcare institutions.

\subsubsection{Cost-effectiveness}

Another construct in the technological context is Cost. It is considered as a significant factor and many organizations perform a cost benefit analysis before taking any important decision regarding the investment in the adoption of innovation $\frac{18}{}$. The basic concept of EHR is mainly in it externality of enterprise integration with lower cost and less programming using existing applications, whereas a significant benefit of application integration is the reduction of overall integration cost $\frac{19}{}$. Although many proposals have been made to control healthcare costs, implementing electronic information systems within the healthcare system is considered the greatest potential for success $^{20}$. The researcher considered formulating the following hypothesis:

H5: Cost- effectiveness will have a negative effect on the adoption of EHR systems in Iraqi healthcare institutions

\subsubsection{Compatibility}

The last effected construct in the technological context is compatibility. It refers to "the degree to which participation in EHR adoption with organizations is perceived as being consistent with existing systems, tasks, and the current needs and objectives of the organizations". It has been considered a critical factor for many of the innovation adoptions. The researcher considered formulating the following hypothesis:
H6: Compatibility will have a positive effect on the adoption of EHR systems in Iraqi healthcare institutions.

\subsubsection{Complexity}

The Complexity of EHR is the third construct in the technological context. It refers to "the degree to which an innovation is perceived as difficult to understand, use and seen as a relatively complicated process" 21 . Usually complexity has a negative effect on diffusion. This means that a more complex innovation has less chance to be successfully diffused in the society. It is also suggested that the perceived complexity of an innovation leads to resistance due to lack of skills and knowledge. Hence, complexity is key considerations for organizations deciding to adopt a new technology. The researcher considered formulating the following hypothesis:

H7: Complexity will have a negative effect on the adoption of EHR systems in Iraqi healthcare institutions.

\subsection{Organization Context}

Within the Organization Context, there are three factors that affect the adoption of EHR systems. These factors are: Organization size, Top Management Support, and IT capability.

\subsubsection{Top Management Support}

The second construct in the Organizational context is top management support. It relates to the commitments coming from the top administration of the health providers to give a great environment that will encourage participation in EHR adoption within their organizations. They play an important role to provide the primary resources that needed when adopting such a new technology innovation. EHR Systems without having help from the top managers, innovation is less possibly to be implemented. The researcher considered formulating the following hypothesis:

H8: Top Management Support will have a positive effect on the adoption of EHR systems in Iraqi healthcare institutions. 


\subsubsection{Size}

Many researchers have been investigated organization size on the introduction of new technologies such as: $\underline{23-}$ 25. In this light, large hospitals have more resources for changing business strategy. Hence hospital size contributed a significant influence on the decision to adopt the EHR systems. Since the size of organization's increases, the complexity and capacity of the facilities needed to continue their operations, and also the demands for their service's increase, justifying the needs for particular information technology's adoption. The researcher considered formulating the following hypothesis:

H9: Organization size will have a positive effect on the adoption of EHR systems in Iraqi healthcare institutions.

\subsubsection{IT Capability}

IT capability in the organizational context refers to the availability of skills, expertise, and technological resources within the local business that makes it easy for participation in EHR adoption with healthcare organizations $^{26}$. It consists of IT employees, physicians, nurses, and IT resources. IT employee's number is an indication for determining whether a health provider has enough IT employees to help support on daily basis operations, perform installations, and handle emergencies, maintenance, and upgrades. IT resources are related to the health provider annual budget of the IT division to install, update, and maintain the organization IS. Most of the earlier studies along with the TOE framework indicate that an organization with a highly level of IT capabilities is usually more probably adopting new technology ${ }^{27}$. The researcher considered formulating the following hypothesis:

H10: IT capability will have a positive effect on the adoption of EHR systems in Iraqi healthcare institutions.

\subsection{Environmental Context}

Within the Environmental context, there are three factors that affect the adoption of EHR systems. These factors are: Culture, Policy, Government support.

\subsubsection{Culture}

In the context of Rogers' framework of the diffusion of innovations, environmental factors can be important correlates of EHR adoption by medical practices. Graetz's work suggests that the culture for innovation and change may be an important correlate of EHR adoption in healthcare ${ }^{28}$. It is speculated that environmental factors, the degree to which its culture emphasizes quality and innovation, would predict EHR adoption. Drivers to change the culture to favor successful EHR adoption were mentioned in several studies. These included cultures change to embrace technology, particularly as EHRs force disruptive change on users, and culturally sensitive issues, such as behavioral patterns, that can impede the implementation process. There is significant structural change to the organizational culture can minimize failure, as can an organization that is open and supportive of change ${ }^{30}$. The researcher considered formulating the following hypothesis:

H11: Culture will have a positive effect on the adoption of EHR systems in Iraqi healthcare institutions.

\subsubsection{Policy}

The policy to use or adapt learning or managerial tools has become increasingly permeated by issues related to technological change. This includes most developing countries to which the policy to use IT resources may change based on the environmental context that serves a particular aim in favoring technology use ${ }^{32}$. Policy interventions create constraints and incentives that influence the process of technological change. And these induced effects of policy on technology may have substantial implications for the positive analysis of the impact of alternative policies, as well as the normative analysis of policy decisions. In Iraq, the lack of standard policy for the use of technology affects the way decision makers looked at the adoption of EHR in the healthcare sectors. The theoretical literature has long recognized that alternative types of policy instruments can have significantly different effects on the rate and direction of technological change. The e-Iraq has included in its future plan a strategy called "legal frames," which 
provides any individual in Iraq with the ability to securely share his/her information. The Iraqi government has developed the Government Interoperability Framework (GIF), a standard document on sharing e-information among government agencies. The researcher considered formulating the following hypothesis:

H12: Policy will have a positive effect on the adoption of EHR systems in Iraqi healthcare institutions.

\subsubsection{Government Support}

Another potentially important factor is Government Support which refers to the role of the government in promoting and encouraging the adoption and usage of EHR within organizations ${ }^{33}$. The role of the government should be considered when making decision to adopt EHR systems in healthcare organizations. The government has provided technical assistance to help some providers adopt, implement, and use EHR systems to improve quality, safety, and efficiency. The governmental is presenting the efforts to maintain and protect the health of the general population. Financial support from the government and payers is critical for additional providers to make an initial investment in e-health such an EHR system. The researcher considered formulating the following hypothesis:

H13: Government support will have a positive effect on the adoption of EHR systems in Iraqi healthcare institutions.

\section{Research Method}

This study used a quantitative approach to collect data from a selected sample of the healthcare providers population in Iraq. The quantitative approach is an effective way of collecting the necessary data because it reflects the opinions of clinical staffs about the use of IT resources, such as EHR system ${ }^{34}$. The quantitative approach is used as a complementary way of collecting adequate data. The quantitative approach is considered objective because it employs a scientific approach to finding reasons for and explanations of particular situations within society ${ }^{35}$. In other words, the quantitative research method significantly reduces the likelihood of personal bias influencing the phenomena of study because it makes it possible for minimal interaction between subject and researcher, which is considered to be the best-suited way of obtaining accurate information when using instruments ${ }^{34}$. This study has used the tool of a questionnaire for data collection, which is considered as the most appreciated technique because of the low cost, use less time, fewer administration efforts inherent in tools and useful to obtain the objectives $\frac{36}{}$. Moreover, a questionnaire has standardized answers, which can make it easy to compile data.

The purpose of this quantitative study is to develop a new model which can help to make the decision to adopt EHR system. The study is intended to provide healthcare management with credible data on the factors affecting the adoption of EHR. The aim of the current chapter is to give the pathway to achieving the research objectives. Furthermore, it introduces the empirical techniques and the research strategy that applied in the study design and also situates the research among existing traditions within information systems.

\subsection{Population and Sample Size}

This study aims to identify the factors that improve the adoption of EHR, particularly in healthcare providers; the study should determine the sample size to represent the population to be investigated ${ }^{37}$.

For the purpose of this research study, the population identified is clinical staffs at the four selected healthcare providers. A total of 3677 clinical staffs represent the population in the selected healthcare providers. The main reason for choosing clinical staffs is because they are the main users of the EHR systems.

The method of determining the sample size is parallel to that proposed by ${ }^{38}$. A minimum sample size of 357 is enough for a population of approximately 3677 clinical staffs. 


\subsection{Validity and Reliability}

Validity and reliability are the parameters used to reduce the inappropriate answers as much as is needed during data collection and testing how good the data is, period. Validity measures the intended measure using an accurate procedure during data collection ${ }^{39}$, and reliability makes the data error free for outcomes that are consistent ${ }^{40}$.

\subsubsection{Validity}

Validity is normally impacted by the survey design. This is due to the fact validity is dependent on questions asked; in addition to the questions developed to measure the aims of study. The majority of surveys include what is related to validity. Hence validity is a clear evidence that can measure properly named as well as measures that are made to measure. In this research study, the researcher employed face as validity test. This is a subjective appearance of how effectively test items relate. Questionnaires applied in this study have been handed out to six experts in the chosen hospitals to check how suitable these questions, their relevance along with if their questions were sensible appropriate.

\subsubsection{Reliability}

Sekaran defines dependability or reliability as "An indication of the stability and consistency with which the instrument measures the concept and helps to access the goodness of a measure" $\underline{39}$. Therefore, to be sure on how accurate the measurement is and to decrease error in the

Table 1. Reliability Testing Results of the Measurement

\begin{tabular}{|c|c|c|c|}
\hline Construct No. & Scale Name & Cronbach's Alpha & No. of Items \\
\hline 1 & Knowledge and Skills & 0.717 & 5 \\
\hline 2 & Training & 0.718 & 7 \\
\hline 3 & Attitudes Towards & 0.722 & 7 \\
\hline 4 & Privacy and Security & 0.804 & 6 \\
\hline 5 & Cost-Effectiveness & 0.843 & 6 \\
\hline 6 & Compatibility & 0.772 & 5 \\
\hline 7 & Complexity & 0.835 & 6 \\
\hline 8 & Top Management Support & 0.716 & 11 \\
\hline 9 & Organization size & 0.709 & 6 \\
\hline 10 & IT Capabilities & 0.773 & 6 \\
\hline 11 & Cultural & 0.863 & 5 \\
\hline 12 & Policy & 0.858 & 5 \\
\hline 13 & Government Support & 0.744 & 5 \\
\hline 14 & EHR Adoption & 0.716 & 8 \\
\hline
\end{tabular}


measurement, one needs to take a very important step of validating the item by checking for reliability.

One common type of dependability, consistency reliability is used more often in the information system domain. Using Cronbach's alphas, the inner consistency was determined according to the calculation of the regular inter-item connections. Dealings are characteristically dependable in the presence of greater correlation amongst other measures or larger Cronbach's alphas. There is no usual limitation point for the alpha coefficient. However, for the Cronbach's alpha the general lower limit of .70. Table 1 shows the results of the reliability analysis. Factors like privacy and Security, Cost-Effectiveness, Complexity, Cultural, and Policy show a high level of reliability. Factors like knowledge and Skills, Training, Attitudes Towards, Compatibility, Top Management Support, Organization size, IT Capabilities, Government Support, and EHR Adoption, show lower reliability. From these results the data is seen to be reliable, and hence further analysis for the supposition tests is accepted.

\subsection{Data Collection}

The study collected the data required to allow the research goals to be achieved by the quantitative means. Identifies this particular process as an approach adopted by researchers to capture and gather empirical research data. Some other researchers such as Rao \& Perry describe it as a data-collection method that takes into account aspects of carrying out the research, ways of collecting the research, required settings in a particular environment, and assigned data sources. In this study, the questionnaire was used as a means of collecting the research data from the healthcare providers in Iraq .

Data collection just after hypothesizing along with deciding on the design of research, the next stage requires the data collection with the reference to every construct in the research hypotheses which are required to be formulated in the study. Before distributing the questionnaires, the researcher explained to the respondents the purpose of the study and the need for data collection. However, the answer rate was not very high because the clinical staffs were busy with daily work-related duties. The ques- tionnaires were personally administered by distributing 600 copies to the clinical staffs. It was distributed to four healthcare providers that are locatedin different regions inIraq which were selected for this study. The most difficulties that affect the data collection are moving through organizations in Iraq because of the current situation, distances from place to place and time were given to the staffs to fill up the questionnaire; some respondents gave 2-3 days to fill it. However, the respondents were placed under no obligation to participate, and those who chose to participate were free to withdraw at any time.

\subsection{Data Analysis}

The analysis is carried out through conceptualization. It requires reasoning and the need to distinguish between data and ideas to maintain that though quantitative analysis needs the usage of ideas, the ideas need to be guided by the data which is being analyzed. The analysis should reflect the content of the collected data. This study has utilized two statistical applications to analyze the collected data and for answering the research questions. The first software program is SPSS, which was used as a statistical analysis software package for the social sciences and information systems. SPSS was chosen because it is a universally recognized computer program for analyzing data. Furthermore, this application was designed to automate the complex formulas and calculations used in various statistics allowing researchers to focus on the research analysis without having to master the arduous intricacies of the statistical functions ${ }^{41}$. Prior research has been conducted using the SPSS program to calculate correlation coefficients to determine the relationships, if any, between independent and dependent variables W.C., 2008; Yuan, et al., 2011. The SPSS version 22 was employed to calculate the statistical results for this study based on the survey data collected .

The second statistic application is AMOS version 22 using Structural Equation Modeling (SEM) which has also been adopted for data analysis to support and validate the result that found using SPSS; it is user friendly in terms of creating the structural models and defining the required statistics ${ }^{42}$; it allows a complete modeling of 
theoretical relationships compared to traditional analyses of merely associating among measures ${ }^{\underline{4}}$; it also provides a straightforward method of dealing with multiple relationships simultaneously while providing statistical efficiency; moreover, it can test the structural model (i.e. the relationship between an independent variable and the dependent variable) and the psychometric properties of the constructs (i.e. the relationship between a latent variable and its indicators). Harris \& Schaubroeck, (1990) proposed a sample size of 200 at least to guarantee robust structural equation modeling. Kline, (2015) suggested that a very complicated path model needs a sample size of 200 or larger while Bagozzi \& Yi (2012) proposed that the sample size should be above 100, preferably above 200. In addition, Yuan, et al (2011) after evaluating different models based on various numbers of respondents opined that a sample size of between 300 and 400 should be appropriate for structural equation models using ordinal data. It can thus be concluded that a minimum and maximum sample of 200 and 400 respectively, is needed for SEM research studies.

\subsection{Survey Response}

The response rate, analyses of the missing and screening data, normality section which proves the normal distribution of the data, the Kaiser-Mayer Olkin test to work out Sampling Adequacy (MSA) trial, lastly the Barlett's test of Sphericity which helps detect the suitable factors in the analysis for the data used in the research is all stated in this section as the outcome of the survey.

\subsubsection{Response Rate}

Clinical staff of the healthcare organizations in Iraqi was the frame of sampling for this research. Out of a sample size of about 600 staffs, $67 \%$ of them submitted their questionnaires and that is 401 of them only questionnaires dropped due to incomplete or random and random answering were thirteen, hence remaining $65 \%$ or 388 beneficial samples. $65 \%$ response is more than enough for the data analyses since the benchmark is $35 \%$ rate according to Chatman (2007).

\subsubsection{Missing and Screening Data}

From the questionnaire, if the data collected for a topic (or case) is unobtainable then it is referred to as Missing Data. In as much as there are rules regarding the answering of questionnaire in other to reduce if not end missing data or two answers for a question, missing data was recorded. This may be as a reason of the overlook or refusal to answer question by the respondents hence the removal of 13 cases.

In order not to obtain distorted results to do errors created by the missing data, those values need to be assessed and also those which fall out of range ${ }^{44}$. Errors checked by the study, were done by conducting frequency analysis for each item. This finally rendered 388 complete data sets from the questionnaires for analysis.

\subsubsection{Normality with Outliers}

A normal distribution assessment is employed for checking how normal the information is. Hierarchical regression analysis, a type of multiple regression analysis will be used in this study and thereby the need of the data set to be checked for its normal distribution. The normal distribution of the data is checked at the early stages of the multivariate analysis by screening constructs incessantly and this stage is essential.

The check for normality is done on each available construct ${ }^{45}$. Skewness test, Histogram test, and A P-P plot test were the three tests employed by the study to confirm the standard and accuracy of the data for further analysis. The symmetry of the dataset was measured by calculating its skewness.

Table 2, shows the range of skewness with no values above the satisfactory assortment of skew as recommended by ${ }^{46}$. That is no value falls from 2.58 to +2.58 with a significance level of 0.01 . With the results obtained from the skewness it confirms the normal distribution of the data hence the opportunity to use them for other analysis. Below is a table showing the results achieved from calculating the skewness of the dataset analyzed.

From this result it is observed that the range of values for skewness of the dataset ranges from -2.544 to 2.342 
Table 2. Skewness- Expressive Statistics of normality

\begin{tabular}{|c|c|c|c|c|c|c|}
\hline Factor & $\mathbf{N}$ & Minimum & Maximum & Mean & $\begin{array}{c}\text { Std. } \\
\text { Deviation }\end{array}$ & Skewness \\
\hline $\mathrm{KaS}$ & 388 & 1.57 & 4.66 & 3.115 & .65656 & -2.544 \\
\hline $\operatorname{Tr}$ & 388 & 1.53 & 4.37 & 2.95 & .56357 & 1.47 \\
\hline AT & 388 & 1.16 & 5.00 & 3.08 & .99758 & 2.342 \\
\hline PaS & 388 & 1.15 & 4.61 & 2.88 & .80876 & 0.454 \\
\hline $\mathrm{CE}$ & 388 & 1.12 & 4.43 & 2.775 & .71175 & 1.145 \\
\hline CB & 388 & 1.22 & 5.00 & 3.11 & .77998 & 1.202 \\
\hline CX & 388 & 1.33 & 4.40 & 2.865 & .91892 & -0.088 \\
\hline TMS & 388 & 1.00 & 5.00 & 3.00 & .84441 & 2.096 \\
\hline OS & 388 & 1.16 & 4.66 & 2.91 & .87682 & 1.92 \\
\hline ITC & 388 & 1.19 & 4.41 & 2.80 & .77291 & 2.082 \\
\hline Cul & 388 & 1.64 & 4.22 & 2.93 & .51782 & 0.86 \\
\hline Pol & 388 & 1.23 & 4.48 & 2.855 & .63137 & 0.332 \\
\hline GS & 388 & 1.32 & 4.32 & 2.82 & .65674 & 0.072 \\
\hline EHR & 388 & 1.18 & 4.51 & 2.845 & .72306 & 0.535 \\
\hline \multicolumn{7}{|c|}{$\begin{array}{l}\text { KaS: Knowledge and Skills, Tr: Training, AT: Attitudes Towards, PaS: Privacy and } \\
\text { Security, CE: Cost-Effectiveness, CB: Compatibility, CX: Complexity, TMS: Top } \\
\text { Management Support, OS: Organization size, ITC: IT Capabilities, Cul: Culture, Pol: } \\
\text { Policy, GS: Government Support, EHR: Adoption of EHR. }\end{array}$} \\
\hline
\end{tabular}

which is an acceptable range. Therefore, the data in each construct is normally distributed.

However, the normality existing between each hypothesis doesn't prove normality in multiple regressions, hence the application of hypothesis testing for further normality test of assumption. For double checking of the data normality, P-P plots and Histogram normality tests have been conducted. Normally distributed data will form a "bell" curve in the histogram test which produces a smooth probability density function applying Kernel smoothing techniques. The histogram generates a line that looks like a bell. The histogram serves as a graphical summary showing the data distribution. The curves of factors are normal. Hence the histogram plot proves the normal distribution of the data with a bell-shaped feature. 
The P-P plot test is a graph that assesses the normality of the data set, hence the third normality test employed for the study. How closely two data sets agree is achieved by a probability plot of the cumulative distribution functions against each other. The diagram generated by the P-P plots shows how closely the little circles follow very well the line with a few random scatters about the line. From this closeness, it is ok for the data to be used for the study purpose. Thus, further analysis can be done with the data which is proven to be normal. The histogram test result and the P-P plots result are seen.

Outliers, referring to the data with values lying outside the normal range data set, were also checked. Also, outliers are described by as "extreme cases which have a considerable impact on the regression solution". Hence a need to determine for outliers of each variable using the Z-score technique. According to, a data is considered as an outlier once Z-score appreciated more or less than the range between \pm 3 . Using this method, no data outlier was seen.

\subsubsection{Kaiser-Mayer-Olkin and Barltett's Test}

The factor analysis needs to be applied to the data set in order to be certain that autonomous variables have important correlations with the reliant variable. To find how suitable the research data is to the factor analysis, the Kaiser- Mayer Olkin's Measure of Sampling Adequacy (MSA) test and Bartlett's Test of Sphericity was used. Measure of Sampling Adequacy is a statistical tool used in identifying the proportions of discrepancy of the study's variables. The filed range of Kaiser-Mayer Olkin's Measure of Sampling Adequacy (MSA) lies between 0 to 1. Below is a measurements assumption;

- A percentage of one represents a mutable that is perfectly predicted with no error by the other mutable.

- A fraction of $.90 \%$ or above is amazing,

- A fraction of $.80 \%$ or above is commendable,

- A fraction of .70\% or above is average,

- A fraction of $.60 \%$ or above is ordinary,

- A fraction of .50\% or above is despondent and,

- A fraction under (.50\%), is intolerable.

For factor analysis the study employs the Kaiser-Mayer Olkin's Measure of Sampling Adequacy (MSA) test and Bartlett's Test of Sphericity which detects the appropriate data. A percentage of 0.823 , which is commendable, was achieved in the study using the Kaiser-Mayer Olkin's Measure of Sampling Adequacy (MSA). This renders the data to be ready for factor analyses.

To discover important associations between the research variables, the Barlett test of Sphericity is employed. The relationship between variables such as related or unrelated is what Barlett test of Sphericity is. This method needs to yield an outcome less than 0.05 to find the significance level of the test. Applying it in the data, it yields a result of 0.000 , giving the opportunity to continue with factor analysis test since it is suitable. Therefore, both test, Kaiser-Mayer Olkin's Measure of Sampling Adequacy (MSA) and Bartlett's tests presents suitable results which meets the basic requirements for

Table 3. KMO and Bartlett's Test

\begin{tabular}{|c|c|c|}
\hline \multicolumn{2}{|c|}{ Kaiser-Meyer-Olkin Measure of Sampling Adequacy } & $\mathbf{. 8 2 3}$ \\
\hline \multirow{3}{*}{ Bartlett's Test of Sphericity } & Approx. Chi-Square & 6189.625 \\
\cline { 2 - 3 } & Df & 65 \\
\cline { 2 - 3 } & Sig. & .000 \\
\hline
\end{tabular}


factor analysis. The outcomes of the test are shown in Table 3.

\subsection{Personals' Profile}

The Demographic aspects considered in the data collection includes sex, age, job title, education level, experience, format of medical records, computer literacy level, and knowledge about EHR. A total of eight demographics in all are integrated in the outcome. The data collected was validated by the parameters of age, experience and education level. Demographic information on the sample was provided by their sex. Participants were differentiated between those who were to be included and those not included by using the demographic factor of job title, computer literacy level, and knowledge about EHR. Format of medical records was included to know how the system in the association was used currently. The expres-

Table 4. Summary of Personal Details

\begin{tabular}{|c|c|c|c|}
\hline Demographic Factor & Category & Frequency & Percent \\
\hline \multirow{2}{*}{ 1. Sex } & Male & 263 & $67.8 \%$ \\
\hline & Female & 125 & $32.2 \%$ \\
\hline \multirow{5}{*}{ 2. Age } & Less than 30 years & 32 & 8.3 \\
\hline & 30 to 39 years & 135 & 34.8 \\
\hline & 40 to 49 years & 121 & 31.2 \\
\hline & 50 to 59 years & 89 & 22.9 \\
\hline & 60 years and older & 11 & 2.8 \\
\hline \multirow{6}{*}{ 3. Job Title } & Physicians & 122 & 31.4 \\
\hline & Nurses & 144 & 37.1 \\
\hline & Pharmacists & 27 & 7.0 \\
\hline & Lab Technicians & 36 & 9.3 \\
\hline & Administration Staff & 33 & 8.5 \\
\hline & Medical Records & 26 & 6.7 \\
\hline \multirow{3}{*}{ 4. Educational Level } & Diploma & 134 & 34.5 \\
\hline & Undergraduate & 166 & 42.7 \\
\hline & Postgraduate & 88 & 22.8 \\
\hline \multirow{4}{*}{ 5. Experiences } & Less than 5 years & 101 & 26.2 \\
\hline & 5-10 years & 178 & 45.8 \\
\hline & $10-15$ years & 67 & 17.2 \\
\hline & More than 15 years & 42 & 10.8 \\
\hline
\end{tabular}


Table 4 Continued

\begin{tabular}{|c|c|c|c|}
\hline \multirow{4}{*}{$\begin{array}{c}\text { 6. Format of Medical } \\
\text { Records }\end{array}$} & Paper & 34 & 8.8 \\
\cline { 2 - 4 } & $\begin{array}{c}\text { Electronic/ } \\
\text { Computerized }\end{array}$ & 158 & 40.7 \\
\cline { 2 - 4 } & Both & 196 & 50.5 \\
\cline { 2 - 4 } & Beginner & 16 & 4.1 \\
\cline { 2 - 4 } $\begin{array}{c}\text { 7. Computer literacy } \\
\text { level }\end{array}$ & Novice & 47 & 12.2 \\
\cline { 2 - 4 } & Intermediate & 171 & 44.0 \\
\cline { 2 - 4 } & Advanced user & 95 & 24.5 \\
\hline \multirow{2}{*}{$\begin{array}{c}\text { 8. knowledge about } \\
\text { EHR }\end{array}$} & Very Little & 59 & 15.2 \\
\hline & A little & 39 & 2.3 \\
\hline & A few things & 217 & 10.1 \\
\hline & A great deal & 123 & 55.9 \\
\hline
\end{tabular}

sive information for each demographic influence in the study is shown in Table 4.

\subsection{Evaluating the Fit of the Model}

To evaluate a model's fitness in observing any data, researchers have brought up a lot of goodness-of-fit indices, but there is no consensus amongst investigators on one index or on a compound of indices to be used as a worldwide quantifier of a model fit ${ }^{47}$. The work by ${ }^{\underline{48}}$ propose that one if not more general goodness-of-fit indices should be used to estimate a model's fit to detected data. Kline (1998) endorsed that at minimum four or more indices to be used such as Goodness of Fit Index (GFI), Normed Fit Index (NFI), Comparative Fit Index (CFI), and Root Mean Square Error of Approximation (RMSEA). Proposed the practice of at least three fit indices so as to replicate different principles and present the best complete image of a model fit. This is done when individual categories of model fit comprise one in itself: absolute, incremental and ungenerous.

\subsubsection{Absolute Fit Indices}

Chi-square $(\chi 2)$ was used to estimate differences amongst covariance formed by the planned model and the anticipated covariance dependent on philosophy. This type of arithmetic index is the maximum important one to evaluate the fit of the model although it has been disparaged for being too sensitive to sample extent $\underline{\underline{49}}$ especially with situations where sample size is greater than 200. Hence most investigators will not exclusively utilize the value of chip-square to castoff or receive their models but use it in combination with extra indices to evaluate the complete fit .

Goodness-of-Fit Index (GFI) which is a second measure of absolute fit index shows the comparative quantity of variance and covariance organized explained by the model. Nevertheless, this index is not accustomed for degrees of freedom. It begins from 0 (representing a poor fit) to 1 (representing a perfect fit), and the proposed level of acceptance is 0.90 . 
Table 5. Summary of Absolute fit indices

\begin{tabular}{|c|c|c|}
\hline Name of the Index & $\begin{array}{c}\text { Level of } \\
\text { Acceptance }\end{array}$ & Comments \\
\hline Chi-square $(\chi 2)$ & $\mathrm{p}>0.05$ & Sample is subtle to large sample scopes. \\
\hline Goodness-of-Fit (GFI) & $>0.9$ & $\begin{array}{c}\text { Outcome near 0 are meagre fit, while } \\
\text { values close to } 1 \text { shows a faultless fit. }\end{array}$ \\
\hline $\begin{array}{c}\text { Root Mean Square Error of } \\
\text { Approximation (RMSEA) }\end{array}$ & $<0.06$ & $\begin{array}{c}\text { If the outcome is less than .06 good fit } \\
\text { is formed }\end{array}$ \\
\hline
\end{tabular}

The third portion, Root Mean Square Error of Approximation (RMSEA) measures the discrepancy designed for each degree of freedom. If the value of Root Mean Square Error of Approximation (RMSEA) is closer to zero, variances and covariance are left less unexplained. Values less than $(<0.1$, preferably $<0.06)$ from the Root Means Square Error of Approximation (RMSEA) indicates the decent fit $\underline{50}$. The RMSEA is the most common amount of model fit as shown in the results and analytics presented in Table 5.

\subsubsection{Incremental Fit Indices}

A comparison between covariance matrix forecasted by model and the detected covariance matrix is done by the Comparative Fit Index (CFI). Table 6 underlines the results associated with the index and level of acceptance whereby the Comparative Fit Indices (CFI) results assort from 0 which is meagre fit to 1 which is faultless fit, with a usually recommended level of 0.90 or greater.

\subsubsection{Parsimonious Fit Indices}

The parsimony of e proposed model fit of parsimonious indices is tested by Normed chip-square $(\chi 2 / d f)$ or (CMIN/DF). This is done by assessing the fit of the model to the amount of projected coefficients essential to attain the level of fit. The variety of outcomes accepted for $\chi^{2} /$ $\mathrm{df}$ ratio is smaller than 5.0 as presented in the results from Table 7.

Table 6. Wrap up of Incremental fit indices

\begin{tabular}{|c|c|c|}
\hline Name of the Index & Level of Acceptance & Comments \\
\hline Comparative Fit Index (CFI) & $>0.90$ & $\begin{array}{c}\text { Outcomes near 0 show a meagre } \\
\text { fit, while values close to 1 show a } \\
\text { faultless fit. }\end{array}$ \\
\hline
\end{tabular}

Table 7. Summary of Goodness-of-Fit Indices (Parsimonious fit indices)

\begin{tabular}{|c|c|c|}
\hline Name of the Index & Level of Acceptance & Comments \\
\hline $\begin{array}{c}\text { Normed chi-square }\left(\chi^{2} / \mathrm{df}\right) \\
\text { CMIN/DF }\end{array}$ & $\leq 5$ (perfect fit) & $\begin{array}{c}\text { Compares chi-square to degrees } \\
\text { of freedom }\end{array}$ \\
\hline
\end{tabular}


To assess a model's fit to detected information this study uses three fit indices which includes one in each of the categories of model fit namely; Root Mean Square Error of Approximation (RMSEA), Comparative Fit Index (CFI), and Normed chip-square ( $\chi 2 / \mathrm{df}$ ) or CMIN/DF as suggested by Hair et al., (2006) so as to reproduce varied criteria and yield the finest general image of model fit .

\section{Hypotheses Testing Results}

Overview of the outcomes in trying the hypotheses for the research is reviewed in this section. All hypotheses are accepted as shown by the results. Thus, significant relationships between the factors (Knowledge and Skills, Training, Attitudes Towards, Privacy and Security,

Table 8. The summarized outcomes of the hypothesis

\begin{tabular}{|c|c|c|c|c|}
\hline $\begin{array}{c}\mathbf{H} \\
\text { Code. }\end{array}$ & Hypothesis Statement & $\beta$-value & Significant level & Results \\
\hline H1 & $\begin{array}{l}\text { Knowledge and skills will } \\
\text { have a positive influence } \\
\text { on the adoption of } \\
\text { EHR systems in Iraqi } \\
\text { healthcare institutions. }\end{array}$ & $\beta=0.586$ & $\mathrm{p}<0.001$ level & Supported \\
\hline $\mathrm{H} 2$ & $\begin{array}{l}\text { Training will have a } \\
\text { positive influence on the } \\
\text { adoption of EHR systems } \\
\text { in Iraqi healthcare } \\
\text { institutions. }\end{array}$ & $\beta=0.843$ & $\mathrm{p}<0.001$ level & Supported \\
\hline H3 & $\begin{array}{l}\text { Attitude toward will have } \\
\text { a positive effect on the } \\
\text { adoption of EHR systems } \\
\text { in Iraqi healthcare } \\
\text { institutions. }\end{array}$ & $\beta=0.765$ & $\mathrm{p}<0.001$ level & Supported \\
\hline H4 & $\begin{array}{l}\text { Privacy and Security will } \\
\text { have a positive influence } \\
\text { on the adoption of } \\
\text { EHR systems in Iraqi } \\
\text { healthcare institutions. }\end{array}$ & $\beta=0.757$ & $\mathrm{p}<0.001$ level & Supported \\
\hline H5 & $\begin{array}{l}\text { Cost-effectiveness will } \\
\text { have a negative influence } \\
\text { on the adoption of } \\
\text { EHR systems in Iraqi } \\
\text { healthcare institutions. }\end{array}$ & $\beta=0.084$ & $\mathrm{P}=.781$ & Not Supported \\
\hline
\end{tabular}


Table 8 Continued

\begin{tabular}{|c|c|c|c|c|}
\hline H6 & $\begin{array}{l}\text { Compatibility will have a } \\
\text { positive influence on the } \\
\text { adoption of EHR systems } \\
\text { in Iraqi healthcare } \\
\text { institutions. }\end{array}$ & $\beta=0.722$ & $\mathrm{p}<0.001$ level & Supported \\
\hline H7 & $\begin{array}{l}\text { Complexity will have a } \\
\text { negative influence on the } \\
\text { adoption of EHR systems } \\
\text { in Iraqi healthcare } \\
\text { institutions. }\end{array}$ & $\beta=0.735$ & $\mathrm{p}<0.001$ level & Supported \\
\hline H8 & $\begin{array}{c}\text { Top Management } \\
\text { Support will have a } \\
\text { positive influence on the } \\
\text { adoption of EHR systems } \\
\text { in Iraqi healthcare } \\
\text { institutions. }\end{array}$ & $\beta=0.727$ & $\mathrm{p}<0.001$ level & Supported \\
\hline H9 & $\begin{array}{l}\text { Organization size will } \\
\text { have a positive influence } \\
\text { on the adoption of } \\
\text { EHR systems in Iraqi } \\
\text { healthcare institutions. }\end{array}$ & $\beta=0.697$ & $\mathrm{p}<0.001$ level & Supported \\
\hline H10 & $\begin{array}{l}\text { IT capability will have a } \\
\text { positive influence on the } \\
\text { adoption of EHR systems } \\
\text { in Iraqi healthcare } \\
\text { institutions. }\end{array}$ & $\beta=0.495$ & $\mathrm{p}<0.001$ level & Supported \\
\hline H11 & $\begin{array}{c}\text { Culture will have a } \\
\text { positive influence on the } \\
\text { adoption of EHR systems } \\
\text { in Iraqi healthcare } \\
\text { institutions. }\end{array}$ & $\beta=0.932$ & $\mathrm{p}<0.001$ level & Supported \\
\hline H12 & $\begin{array}{l}\text { Policy will have a positive } \\
\text { influence on the adoption } \\
\text { of EHR systems in Iraqi } \\
\text { healthcare institutions. }\end{array}$ & $\beta=0.848$ & $\mathrm{p}<0.001$ level & Supported \\
\hline H13 & $\begin{array}{l}\text { Government support } \\
\text { will have a positive } \\
\text { effect on the adoption } \\
\text { of EHR systems in Iraqi } \\
\text { healthcare institutions. }\end{array}$ & $\beta=0.611 S$ & $\mathrm{p}<0.001$ level & Supported \\
\hline
\end{tabular}


Cost-Effectiveness, Compatibility, Complexity, Top Management Support, Organization size, IT Capabilities, Culture, Policy, Government Support) and the Adoption of EHR exists. Table 8 shows the summary of the hypothesis tests.

\section{Conclusion}

The research investigated the factors that influence the EHR adoption in Iraqi healthcare providers. Based on the analysis of the literatures of adoption of EHR and well-established models and theories such as TOE framework, DOI theory, and Institutional Theory, Theory of Reason Action (TRA), Technology Acceptance Model, and Social Exchange, 12 hypotheses have been developed. The findings of the study revealed that Knowledge and Skills, Training, Attitudes towards Privacy and Security, Cost-Effectiveness, Compatibility, Complexity, Top Management Support, Organization size, IT Capabilities, Culture, Policy and Government Support have significant relationships with adoption of EHR in Iraqi healthcare organizations. By achieving the objectives of this study, the research questions are answered. Explanations and discussions are provided based on the findings. Results of this research have both academic and practical implications; and make contributions to both academia and health practice.

The findings of the research are essential and relevant to the IT managers, and any other IT personal of these organizations. These findings give a high contribution to both healthcare providers and governments in terms of planning and implemented high impact strategies; from the technological aspects, as well as from the organizational and sustainability aspects to be able to increase the participation and usage of EHR systems among them. The chapter concluded with the research limitations and outlined some directions for further research, followed by the overall conclusion. Finally, the coherence with the study methods applied gives credibility to the findings and enhances the knowledge and insights gained in this study.

\section{References}

1. Gagnon M-P, Ouimet M, Godin G, Rousseau M, Labrecque M, Leduc Y, Abdeljelil AB. Multi-level analysis of electronic health record adoption by health care professionals: a study protocol. Implementation Science. 2010 April; 5(1):1-30. https://doi.org/10.1186/1748-5908-5-30. PMid:20416054 PMCid:PMC2873301.

2. Alvarez R. The electronic health record: a leap forward inpatient safety. Healthcare Papers. 2004; 5:33-36. https://doi. org/10.12927/hcpap.2004.16862. PMid:16278533

3. Urowitz S, Wiljer D, Apatu E, Eysenbach G, De Lenardo C, Harth T, Leonard KJ. Is Canada ready for patient accessible electronic health records? A national scan. BMC medical informatics and decision making. 2008; 8(1):1-33. https://doi.org/10.1186/1472-6947-8-33. PMid:18652695 PMCid:PMC2532996

4. Boonstra A, Broekhuis M. Barriers to the acceptance of electronic medical records by physicians from systematic review to taxonomy and interventions. BMC health services research. 2010; 10(1):1-231. https://doi.org/10.1186/14726963-10-231. PMid:20691097 PMCid:PMC2924334

5. Erstad TL. Analyzing computer-based patient records: A review of literature. Journal of Healthcare Information Management. 2003; 17(4):51-57. PMid:14558372

6. Strudwick G, Eyasu T. Electronic health record use by nurses in mental health settings: a literature review. Archives of psychiatric nursing. 2015; 29(4):238-41. https://doi. org/10.1016/j.apnu.2015.03.007. PMid:26165979

7. Neil S. Better medicine through machine learning. Communications of the ACM. 2012; 55(1):17-19. https:// doi.org/10.1145/2063176.2063182.

8. Biondich P, Fraser H, Moodley D, Choi S, Mamlin B, Szolovits P. Implementing electronic medical record systems in developing countries. Journal of Innovation in Health Informatics. 2005; 13(2):83-95. https://doi.org/10.14236/ jhi.v13i2.585

9. OpenClinical. Electronic medical records, electronic health records. Date accessed: 12/10/2005: Available from: http:// www.openclinical.org/emr.html\#refs.

10. Mohamud K. Electronic health records in Trinidad and Tobago. Saint Mary's University of Minnesota. 2014; 198:1373.

11. Scott BJG. Can Developing Countries Overcome the Digital Divide? Information Technology in Trinidad and Tobago. Western Journal of Black Studies. 2006; 30(2):75-79.

12. Rottman JW, Jeyaraj A, Lacity MC. A review of the predictors, linkages, and biases in IT innovation adoption research. Journal of Information Technology. 2006; 21(1):123. https://doi.org/10.1057/palgrave.jit.2000056 
13. Riddell MC, Sandford KG, Johnson AO, Steltenkamp C, Pearce KA. Achieving meaningful use of electronic health records (EHRs) in primary care: Proposed critical processes from the Kentucky Ambulatory Network (KAN). The Journal of the American Board of Family Medicine. 2014; 27(6):772-9. https://doi.org/10.3122/ jabfm.2014.06.140030. Mid:25381074

14. Vuk J, Anders ME, Mercado CC, Kennedy RL, Casella J, Steelman SC. Impact of simulation training on self-efficacy of outpatient health care providers to use electronic health records. International journal of medical informatics. 2015; 84(6):423-29. https://doi.org/10.1016/j. ijmedinf.2015.02.003. PMid:25746460

15. Musen MA, Middleton B, Greenes RA. Clinical decisionsupport systems. Biomedical informatics. 2014; p. 643-74.

16. Rognehaugh $\mathrm{R}$. The health information technology dictionary. Gaithersburg, MD: Aspen Publishers. 1999

17. Begum M, Mamun Q, Kaosar M. A privacy-preserving framework for personally controlled electronic health record (PCEHR) system. Australian E health Informatics and Security Conference. 2013; p. 1-9.

18. Lehmann CU, O'Connor KG, Shorte VA, Johnson TD. Use of electronic health record systems by office-based pediatricians. Pediatrics. 2015; 135(1): e7-e15. https://doi. org/10.1542/peds.2014-1115. PMid:25548325

19. Bergmo TS. How to measure costs and benefits of eHealth interventions: an overview of methods and frameworks. Journal of medical Internet research. 2015; 17(11):1254. https://doi.org/10.2196/jmir.4521. PMid:26552360 PMCid:PMC4642791

20. Christensen HB, Christensen M, Hansen KM, Kyng M, Manikas K, Surrow M, Urazimbetova S. Requirements for a software-intensive ecosystem for telemedicine. Global Telemedicine and eHealth Updates : Knowledge Resources. 2012; 5:423-27.

21. Rogers. Diffusion of Innovations. 5th Edition. New York, NY: Free Press. 2003.

22. Alshehri M, Drew S. E-Government fundamentals. Paper presented at the IADIS International Conference ICT, Society and Human Beings. 2010; p. 1-9.

23. Belso-Martinez JA. Outsourcing decisions, product innovation and the spatial dimension: evidence from the Spanish footwear industry. Urban Studies. 2010; 47(14):3057-77. https://doi.org/10.1177/0042098009359952

24. Borgman HP, Bahli B, Heier H, Schewski F. Cloudrise: exploring cloud computing adoption and governance with the TOE framework. 46th Hawaii International Conference on System Sciences. 2013; p. 4425-35. https:// doi.org/10.1109/HICSS.2013.132

25. Nedev S. Exploring the factors influencing the adoption of Cloud computing and the challenges faced by the business.
Enquiry-The ACES Journal of Undergraduate Research. 2014; 5(1):1-45.

26. Kamal MR, Singh D, Ahmad K. Factors Influencing Interdepartmental Information Sharing Practice in Electronic Government Agencies. International Conference Knowledge Management. 2012; p. 1-7. PMid:22688441

27. Kamal. IT innovation adoption in the government sector: identifying the critical success factors. Journal of Enterprise Information Management. 2006; 19(2):192-222. https://doi. org/10.1108/17410390610645085

28. Graetz I, Reed M, Shortell SM, Rundall TG, Bellows J, Hsu J. The association between EHRs and care coordination varies by team cohesion. Health services research. 2014; 49(1-2):438-52. https://doi.org/10.1111/1475-6773.12136. PMid:24359592 PMCid:PMC3925412

29. Heath M, Appan R. Impact of information technology culture conflict on meaningful use of electronic health records system: A conceptual framework. Healthcare Information Systems and Technology. 2014; p. 1-10. PMid:25543676

30. Nguyen L, Bellucci E, Nguyen LT. Electronic health records implementation: an evaluation of information system impact and contingency factors. International journal of medical informatics. 2014; 83(11):779-96. https://doi. org/10.1016/j.ijmedinf.2014.06.011. PMid:25085286

31. Kraft MME. Environmental policy and politics: Taylor \& Francis. 2017.

32. Mickwitz P. A framework for evaluating environmental policy instruments: context and key concepts. Evaluation. 2013; 9(4):415-36. https://doi.org/10.1177/1356389003094004

33. Fleischer MT, Chakrabarti AK. Processes of technological innovation: Lexington Books. 1990.

34. Pertwee R. The ring test: a quantitative method for assessing the 'cataleptic' effect of cannabis in mice. British Journal of Pharmacology. 2012; 46(4):753-63. https://doi. org/10.1111/j.1476-5381.1972.tb06900.x

35. Sherley J, Stadler P, Stadler JS. A quantitative method for the analysis of mammalian cell proliferation in culture in terms of dividing and non-dividing cells. Cell Proliferation. 2008; 28(3):137-144. https://doi.org/10.1111/j.1365-2184.1995. tb00062.x

36. Gutierrez A, Boukrami E, Lumsden R. Technological, organisational and environmental factors influencing managers' decision to adopt cloud computing in the UK. Journal of Enterprise Information Management. 2015; 28(6):788-807. https://doi.org/10.1108/JEIM-01-2015-0001

37. Abdekhoda M, Ahmadi M, Gohari M, Noruzi A. The effects of organizational contextual factors on physicians' attitude toward adoption of Electronic Medical Records. Journal of biomedical informatics. 2015; 53:174-79. https://doi. org/10.1016/j.jbi.2014.10.008. PMid:25445481 
38. Krejcie RV, Morgan DW. Determining sample size for research activities. Educational and Psychological Measurement. 1970; 30:607-10. https://doi. org/10.1177/001316447003000308

39. Sekaran U. Research Methods for Business: A Skill Building Approach. 5th Edition. United Kingdom: Wiley-India. 2009. PMCid:PMC2681117

40. Bagozzi RP, Yi Y. Specification, evaluation, and interpretation of structural equation models. Journal of the academy of marketing science. 2012; 40(1):8-34. https:// doi.org/10.1007/s11747-011-0278-x

41. Yuan KH, Wu R, Bentler PM. Ridge structural equation modelling with correlation matrices for ordinal and continuous data. British Journal of Mathematical and Statistical Psychology. 2011; 64(1):107-33. https:// doi.org/10.1348/000711010X497442. PMid:21506947 PMCid:PMC3103762

42. Byrne BM. Structural equation modeling with AMOS, EQS, and LISREL: Comparative approaches to testing for the factorial validity of a measuring instrument. International journal of testing. 2001; 1(1):55-86. https://doi.org/10.1207/ S15327574IJT0101_4

43. Weerakkody V, Carter L. E-government adoption: A cultural comparison. Information Systems Frontiers. 2008;
10(4):473-82. https://doi.org/10.1007/s10796-008-9103-6

44. Kline RB. Principles and practice of structural equation modeling: Guilford publications. 2015.

45. Tabachnick B, Fidell L. Using Multivariate Statistics, 5th Edition. Pearson: Boston, MA. 2007. PMCid:PMC2724990

46. Hair JF, Black WC, Babin BJ, Anderson RE, Tatham RL. Multivariate data analysis. Pearson Prentice Hall Upper Saddle River, NJ. 2006, 6.

47. Shah R, Goldstein SM. Use of structural equation modeling in operations management research: Looking back and forward. Journal of Operations Management. 2006; 24(2):148-69. https://doi.org/10.1016/j.jom.2005.05.001

48. Anderson JC, Gerbing DW. Structural equation modeling in practice: A review and recommended two-step approach. Psychological bulletin. 1988; 103(3):1-411. https://doi. org/10.1037/0033-2909.103.3.411

49. Jöreskog KG, Sörbom D. PRELIS 2-A guide to the program and application. Manuscript in preparation. Chicago: Scientific Software International. 1996

50. Brown GT. Teachers' Conceptions of Assessment: Validation of an Abridged Version. Psychological Reports. 2006; 99(1):166-70. https://doi.org/10.2466/pr0.99.1.166-170. PMid:17037462 